\title{
Mapping Green Infrastructure Based on Multifunctional Ecosystem Services: A Sustainable Planning Framework for Utah's Wasatch Front
}

\author{
Richard leBrasseur (D)
}

Department of Plant, Food and Environmental Sciences, Faculty of Agriculture, Dalhousie University, Truro, NS B3H 4R2, Canada; r.lebrasseur@dal.ca

\begin{abstract}
Most sustainable planning frameworks assess natural and social-economic landscape systems as separate entities, and our understanding of the interrelationships between them is incomplete. Landscape classification in urbanizing environments requires an integrated spatial planning approach to better address the United Nation's sustainable development challenges. The objective of this research is to apply a multicriteria evaluation which ranked diverse ecosystem-service producing landscapes and synthesize the findings within a unique green infrastructure spatial planning framework. Local government stakeholder derived weighting and GIS classification were operated to map both the urban and natural landscapes of the Salt Lake City region of Utah, one of the most rapidly urbanizing areas in North America. Results were assimilated through five regional landscape typologies-Ecological, Hydrological, Recreational, Working Lands, and Community—and indicated those highest ranked landscape areas which provided multiple ecosystem services. These findings support collaborative decision making among diverse stakeholders with overlapping objectives and illustrates pathways to the development of ecosystem service criteria. This paper contributes to a better understanding of how to integrate data and visualize the strategic approaches required for sustainable planning and management, particularly in urban and urbanizing regions where complex socioecological landscapes predominate.
\end{abstract}

Keywords: ecosystem services; green infrastructure; multicriteria evaluation; GIS mapping; multifunctional landscapes; sustainable planning

\section{Introduction}

Urban landscapes are social-ecological systems [1] and occur across much of the world [2]. Nearly two thirds of the world's population is expected to live in cities by 2050 [3], including $89 \%$ of the population within the USA, requiring sustainable growth to ensure environmental integrity, ecological function, [4] and human wellbeing [5]. Urban landscapes have high spatial heterogeneity [6] as well as demographic and social diversity, impacting resource access and function [7]. The ecosystem services (ES) framework assesses ecosystem benefits by translating ecological structures, functions, and processes into value based operations and objects [8]. Ecosystem services include supporting services (e.g., soil formation and nutrient cycling), provisioning services (e.g., food, fresh water, fuel, fiber, and other goods), regulating services (e.g., climate, water, and disease regulation as well as pollination), and cultural services (e.g., educational, aesthetic, and cultural heritage values as well as recreation and tourism) [9].

Many models and theoretical constructs within ecosystem services exist, most are predominately ecological frameworks or anthropocentric frameworks [10]. Most ecosystem services frameworks evaluate single function landscapes [11], not multifunctionality nor the wider range of ecosystem services available [12,13]. In urban landscapes, ecosystem services originate from multiple and diverse biophysical, social, economic, political, and cultural landscape features that fluctuate with spatial scale [14]. The interrelationships between 
these diverse landscapes regulate ecosystem functions [4,15], which provide benefits, or ecosystem services, to populations [16]. The need for an integrated, comprehensive assessment of ecosystem services is increasingly acknowledged [17,18].

Established land suitability analyses commonly applied in spatial planning (e.g., hierarchical, ordinal) do not fully represent the diversity of ES related functions and benefits [19] and have limited capacity to quantify the multifaceted relationship between social and ecological systems [20]. Multifunctionality, however, acknowledges the supply of a diverse set of ecosystem services which lead to numerous environmental, social, and economic benefits. Multifunctional landscapes integrate ecosystem services and human wellbeing, they support livelihoods, protect species, and provide recreational needs [21,22]. Multifunctional landscapes are characterized by diverse land use and complex landscape structure, thereby including the many, often competing, interests and values of different landowners and stakeholder groups. Multifunctional landscape analyses are better able to interpret the complexity of their socioecological systems and their values. Overall, a multifunctional landscape approach to ecosystem services assessment increases sustainable development strategies [23].

Literature supports a comprehensive planning approach which includes multifunctional ecosystem service assessment [24,25]. However, the application of an ecosystem services approach to landscape analysis, sustainable planning, and decision making is still lacking in the spatial planning process [26-28]. During the past decade, many spatial landscape frameworks and environmental planning tools have been developed which incorporate the concept of ecosystem services [29]. Few, however, have comprehensively captured the diversity of ecosystem services, particularly within urban and urbanizing landscapes [30,31]. In China, urban greenspace system planning has been placed within urban planning and serves to control urban sprawl and improve urban ecosystem services but lacks the inclusion of nonbuilt greenspaces such as forests and wetlands [32]. Elsewhere, in Berlin, Germany, concrete decisions and management actions did not result from the ES assessment used. Here, only informal planning strategies could be agreed upon due to unclear and disagreed upon ecosystem service outcomes among a diverse stakeholder group [33]. Other barriers to ES planning integration and operationalization strategies remain and include a lack of understanding for exactly how ES informs decision making [34] and at which point the ES concept should be applied [28]. Overall, there is a continued need to examine and define possible methods and tools for ecosystem service assessment in planning and policy documents e.g., [26,35,36]. Literature's different methods used for ES classification and mapping limit the comparability of outcomes and call for a more consistent but flexible approach [37-39].

This recognition has led to the concept of "Green Infrastructure" (GI) [40] to help manage functional ecosystems through strategic land use planning. GI encompasses an interconnected network of natural, seminatural, and artificial ecosystems and greenspaces within, around, and between environments, at varying spatial scales [41,42]. These GI areas can be managed to deliver a wide range of ecological, social and economic benefits or ecosystem services [5]. Overall, GI is able to improve the environmental quality, livability, and sustainability of people and communities through multifunctionality [43]. The GI concept is a valuable tool for "translating" the complex topic of ES into more comprehensible terms and is better suited to convey ES language to diverse stakeholders and disciplines [29]. Furthermore, GI can be spatially mapped and applied towards sustainable planning policy.

This study's research questions, thus, are: (1) How can the concepts of green infrastructure and multifunctional ecosystem services support the conceptualization of a decisionmaking framework among diverse stakeholders? and (2) What are the available tools which advance the documentation, communication, and application of ecosystem services in policy, sustainable planning, and management? The goal of this paper was to develop and test a framework or methodology which integrates qualitative and quantitative ecosystem service information to create a hierarchical green infrastructure based spatial map. 


\subsection{Green Infrastructure as a Framework for Multifunctional Ecosystem Service Analysis}

One of the main strengths of GI is its landscape multifunctionality, i.e., promoting spatial areas that can serve more than one purpose, such as climate change mitigation, biodiversity conservation, food production, the creation of recreational greenspaces, and provide employment opportunities [44]. GI addresses multiple demands and contributes to finding solutions for a range of environmental, social, and economic pressures [45]. Multifunctionality, here, is described as the capacity of green infrastructure to provide multiple ES [46] and is regarded as a core principle of the GI approach [47-49]. Multifunctionality is closely related to physical connectivity. Connectivity is important to GI and the delivery of ecosystem services through the concept of flows [50,51]. This connectivity supports and enhances GI; it increases ecological resilience to stressors from urbanization and climate change [52] and strengthens regional economic stability [53]. As an interconnected landscape framework which can assess ecosystem services, the GI framework emphasizes the quality and quantity of these diverse landscapes, as well as their multiple functions and the importance of interconnections between them [42,54].

Notably, if systematically planned, developed, and maintained, GI has the potential to contribute to ecosystem services and sustainability [55]. GI is able to identify the positive synergies among ecosystem services found within diverse landscapes [56]. However, literature demonstrates that consistently quantifying multifunctionality, even within the GI framework, is difficult [57], as is operationalizing multifunctional ES within spatial planning [58]. The concept of GI has been interpreted divergently and no consensus regarding GI's components nor a method to identify and map GI has been reached [59]. For example, biodiversity as a key ecosystem service is often assessed through strictly ecological benefits and planning considerations (e.g., connectivity, species diversity), which does not capture societal values such as socioemotional wellbeing and human disease resilience [60]. These and other synergistic benefits within GI remain difficult to document and quantify.

\subsection{Multifunctional Landscapes and Multicriteria Analysis}

To address these issues, concepts within multicriteria decision analysis (MCDA) and multicriteria evaluation (MCE) provide an approach to collectively analyze landscape features and ecosystem services [61]. These methods are often used to support complex decision-making situations with multiple and often conflicting objectives that stakeholder groups value differently. MCE methods are able to address intangible values such as cultural and heritage ecosystem services [62] as well as aspects of human wellbeing [63,64]. MCE allows the comparison of ecosystem services with sociocultural and economic values in a structured and shared framework [65-67], as well as the evaluation of quantitative and qualitative information [68,69]. MCE methods are integrative evaluation methods, e.g., [66]; they combine criteria scoring with contextual weighting and are often used in spatially explicit landscape models of ecosystem services such as GIS [70,71]. MCE approaches can synthesize GI's multifunctional ES information and better clarify the gap of stakeholder communication and knowledge. They comprehensively assess the landscape's interrelationships in order inform sustainability, spatial planning, management, and policy [37].

The objective of this paper is to implement an MCE in order operationalize GI's multifunctional ES analysis, assessment, and mapping. This methodology was applied to a case study area and served to classify multifunctional landscape features using multicriteria analyses in a GIS environment. Stated succinctly, an ecosystem services assessment based on stakeholder defined weighting was used to map the results though green infrastructure planning principles. The research included:

1. Collect, analyze, and review data to synthesize a set of interrelated sustainable landscape planning goals based on ecosystem services;

2. Provide a framework to evaluate multifunctional landscapes using MCE which evaluates multiple ecosystem services based on a range of stakeholder values; 
3. Model the results in GIS based on green infrastructure components.

The structure of this paper is as follows. First, the theoretical basis for an integrated GI approach which recognizes multifunctional ecosystem services is followed by a brief overview of multicriteria decision-making concepts and their utility in ecosystem service analysis. Next, the case study's methods are explained, and an interrelated ecosystem services framework is developed in order to operationalize composite ES indicators. This framework was tested on a case study in the Salt Lake City region of Utah in the United States and the results are spatially presented through a succinct set of GIS maps. This paper closes with a discussion of applications, lessons learned, as well as main conclusions.

\section{Materials and Methods}

\subsection{Study Area}

The Wasatch Front region of Utah includes Weber, Morgan, Davis, Salt Lake, and Tooele Counties with 59 municipalities and is home to nearly 2.6 million residents within $6,397,316$ acres $(2,588,900 \mathrm{ha})$. This study area included the region's largest city, Salt Lake City, the capital of Utah, and other major cities of West Valley City, Provo, West Jordan, Layton, and Ogden. Between 2010 and 2019, the region grew nearly 12\% [72] in population size, with Utah County growing the most at 26.1\%. [72]. Utah continues to have the largest household size in the nation at 3.19 [72] and is considered one of the fastest growing regions in the United States [72].

The changes associated with increased population and human development have impacted the landscape, including reduced water quantity and quality [73], and placed added strain on the air quality within the Wasatch Front [74]. There has been deforestation [75] and increased impervious surface coverage [76] and heat-island affects [77] from roof and asphalt surfaces. Furthermore, the region has experienced the overcrowding of homeless shelters [78], increased wait times for emergency services [79], and a greater number of major psychological depression cases [80].

The methodological framework for this study is presented in Figure 1. In Step 1, the regional landscape planning goals were reviewed and synthesized from multiple sources. Five interrelated regional landscape categories or typologies were also designated. These were approved by a technical advisory committee (TAC) made up of various local government stakeholders. In Step 2, the landscape typologies from Step 1 were further classified and assigned specific, spatially delineated areas through GIS data. From this, a set of unique direct and indirect ecosystem services was synthesized and a multicriteria analysis matrix was developed. This matrix served to format the TACs hierarchical rankings for the relationship between the regions landscape classifications and the regions ecosystem services. The data was then reviewed and reclassified in Step 3 as part of the geovisualization process. In Step 4, each regional landscape typology dataset was GIS modelled within the green infrastructure framework of cores, hubs, and corridors to create a set of five individual green infrastructure maps.

The TAC was the core committee for this project and approved all steps, methods, and provided the data and criteria ranking. The TAC was purposefully a multidisciplinary, stakeholder based, multiagency committee (Table S1); nearly 40 committee members included federal, state, regional, local government and nongovernment directors, as well as specific staff and scientists knowledgeable in contextual issues such as water quality, mammal habitat, and agricultural production, for example. Their role was to evaluate and respond to the study's methods, criteria development, and ranking, and ensure they met both their individual and overall regional planning goals. Additionally, specific experts of the TAC were consulted at various steps in order to clarify both the ecosystem service and its relationship to the specific landscape typology, such as whether the landscape classification provided a direct or indirect ecosystem service. For instance, in Step 2, experts from the US Fish and Wildlife Service were consulted in developing appropriate landscape classifications (e.g., reservoirs, lakes, aquifer discharge areas) and they provided GIS data. Additionally, experts from the City of Salt Lake and Utah Department of Natural Resources 
Water Division were consulted to develop hydrological ecosystem service outputs used to develop the criteria matrix (e.g., flood control, water quality, supply). In Steps 3 and 4, TAC members reviewed the matrix, ensured ecosystem services criteria were appropriate, and modified the ranking if necessary, leading to the GI mapping. Ultimately, a large group of diverse experts within the TAC was continuously integrated into the process and the study's framework.

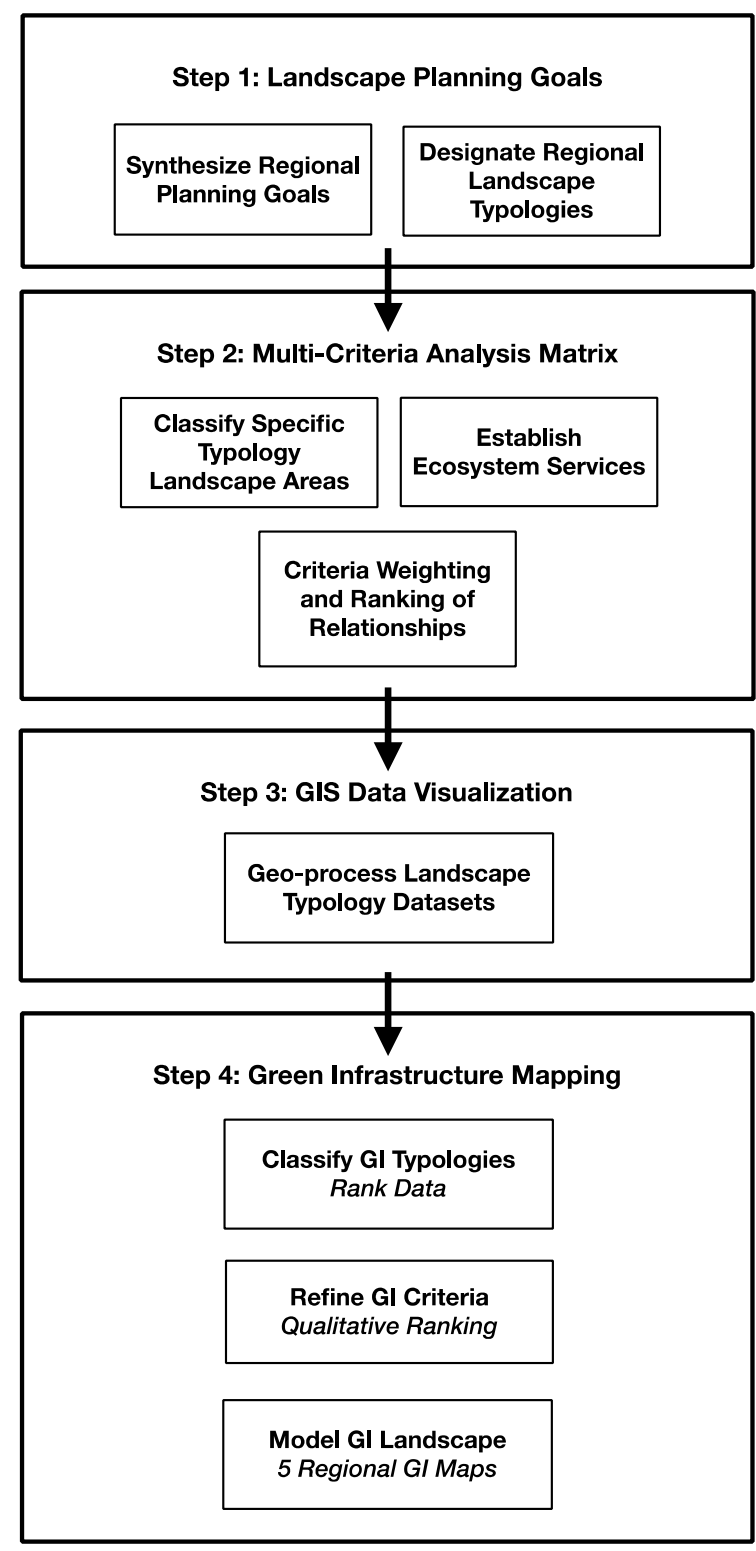

Figure 1. The framework of the study procedure.

\section{Step 1: Landscape Planning Goals}

The first step required the synthesis of regional planning goals and to designate regional landscape typologies by the TAC. This was completed concurrently through the review of over 50 reports, plans, policy documents, strategic plans, and others of the various stakeholders, including federal, state, municipal, and local agencies, as well as community groups and NGOs (Table S1). Specifically, these were reviewed in order to identify overlapping concerns, goals, and objectives; ultimately providing the basis for the study's integrated regional planning goals and the 5 overarching regional landscape typologies. Scheme 1 summarizes the Wasatch Front region's five overall landscape 
typologies-Ecological, Hydrological, Recreational, Working Lands, and Community_and their landscape planning goals.

\section{Ecological Network Goal}

A. To protect and enhance the natural landscapes, ecosystems, and biodiversity of the Wasatch Front, providing habitat for the region's plant communities, wildlife and fisheries, including unique ecological communities, rare, threatened or endangered species, and other areas of environmental concern.

\section{Hydrological Network Goal}

A. To protect and enhance the water resources of the Wasatch Front, including watersheds, wetlands, groundwater and source water areas, to ensure water quality, and to provide a continually safe and abundant water supply for our communities.

B. To promote a healthy hydrological system which encourages efficient flood control and water conveyance, while providing clean water, wildlife habitat, and recreational uses.

\section{Recreational Network Goa}

A. To protect and enhance the parkland, open space, connecting lands and water corridors of the Wasatch Front; to provide outdoor recreation opportunities such as fishing, hunting, wildlife viewing, paddling, camping, and trail-based activities.

B. To strengthen the vibrant network of parks, trails, scenic qualities, recreation amenities, and natural lands in the Wasatch Front.

\section{Working Lands Network Goal}

A. To protect the working lands of the Wasatch Front, including the forests, orchards, rangelands, and agricultural lands, to support their economic viability, to maintain the benefits provided, and retain the rural character of the region.

\section{Community Network Goal}

A. To promote the development of healthy communities, both urban and rural, including the counties, cities, towns, parks, faithbased activities, commercial areas, and transit systems in the Wasatch Front - places where we live, work and gather.

B. To preserve and strengthen the cultural resources, both built and natural, as well as the heritage and sense of community in the Wasatch Front.

C. To preserve the economic health of our region, and to protect municipal budgets by enhancing the value and benefits of an interconnected system, and sustaining the community lifestyles they provide.

Scheme 1. The 5 regional landscape typologies and their regional planning goal.

\section{Step 2: Multicriteria Analysis Matrix}

Step 2 developed a multicriteria analysis approach to quantify the relationship between specific landscape typologies areas. This included a more detailed landscape classification specifically correlated to their ecosystem service benefits. This multicriteria evaluation (MCE) was organized within a matrix format shown in Scheme 2 with the vertical axis listing the regional landscape's classifications found within each of the 5 typologies and the horizontal axis listing the region's ecosystem services specific to those landscape classifications.

The landscape classification included 41 unique spatial typologies and was correlated to the information and description within the 28 GIS datasets and their geospatial polygons provided by the TAC (Table S3). This is operationalized and clarified later in this paper. This process provided a meaningful generalized classification to the regional landscape typologies and was not a detailed description or inventory. The classification of the GIS data provided the basis to operationalize the matrix in Step 3. Importantly, this spatial data was able to express different compositions of the same component, such as wetlands found within the conservation easements and wildlife habitat (Scheme 2-vertical axis) of the ecological landscape typology (Scheme 1), the agricultural easements of the working landscape typology (Schemes 1 and 2-horizontal axis), as well as the many features within the hydrological landscape typology (i.e., aquifer research areas, conservation easements, drinking water protection zones). This overlap allowed for the influence of ecosystem services to be more comprehensively documented. 


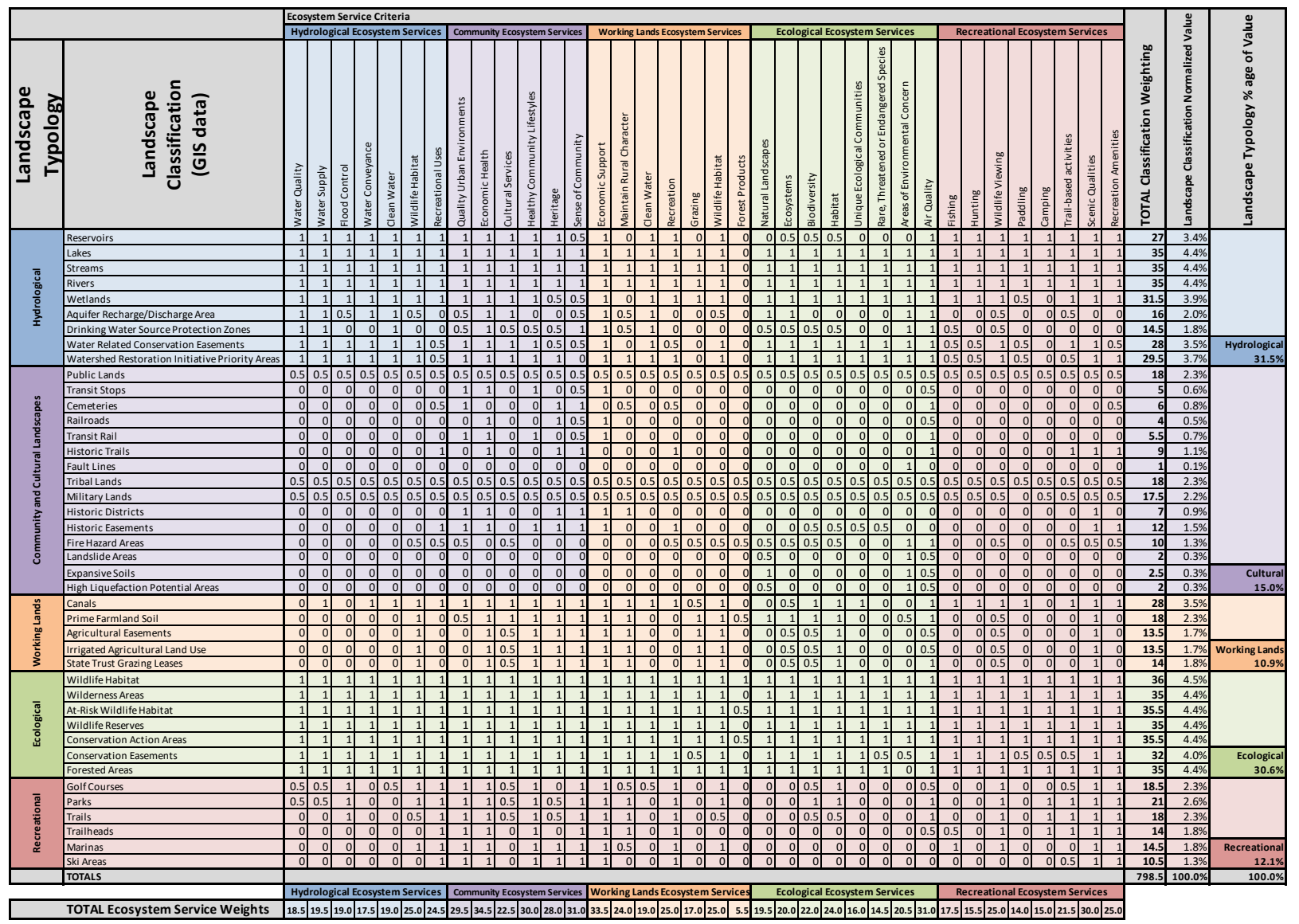

Scheme 2. Landscape typologies and ecosystem service criteria and ranking. Scheme 2's matrix illustrates the 41 landscape typologies in the vertical axis and the 36 ecosystem services of the five landscape networks in the horizontal axis.

The ecosystem services included 36 total "benefits", organized specifically to each typology and their landscape classifications, and were developed by the TAC from the critical review in Step 1. It is important to note that this list of 36 ecosystem services was specifically designed to integrate diverse stakeholders into the evaluation and assessment process by purposefully using language commonly found within the reviewed documents (Table S1) and inclusive of the ecosystem service concepts found within the regional planning goals (Scheme 1). These 36 ecosystem services are not standard ES classifications per the Millenium Ecosystem Assessment (MEA), the Common International Classification of Ecosystem Services (CICES), and other applied ES frameworks, though similar. As noted within the literature, ES classification should ultimately improve stakeholder communication and knowledge. This study's development of its 36 ecosystem services was deliberate in its simplicity and clarity, and captured both direct and indirect ecosystem services among and between varied landscape types. This was a unique approach and a significant contribution of this paper.

\subsection{Criteria Weighting and Ranking}

Once the matrix's criteria were established, weighted values were applied to each landscape classification (vertical axis) and specific ecosystem service (horizontal axis). The weighted values were either ranked " 1.0 " indicating a direct relationship between landscape classification and ecosystem service or " 0.5 " for an indirect relationship. An " 0.0 " indicated no relationship existed. Within the traditional ecosystem service categories per MEA, a direct relationship was considered a "provisioning service" or "cultural service" and an indirect relationship was considered a "regulating service" or "supporting service". 
Though other weighting methods exist, such as suitability analysis, this ranking criteria of 0.5 and 1 was agreed upon by the TAC and represented a simplified approach to ranking or coding of the data. Any type of codification could be applied; this study's simple measure was agreed upon by the TAC to clearly document the direct and indirect aspects of the ES. Stakeholder experts and the authors of these documents were consulted specifically to review and determine the criteria ranking. These values were finalized by the TAC and supported through the information within Table S1.

Scheme 2 summarized the results for both the direct and indirect ecosystem services provided by the landscape typologies. For example, the hydrological landscape's aquifer recharge areas provided the direct ecosystem service (1.0) of "water supply" or "clean water" but indirectly impacted (0.5) "wildlife habitat" within the ecological landscape. Notable within this process, certain landscape classifications provided ecosystem services to other landscape classifications besides their own. Trails were listed in the recreational landscape typology, but received a weighted value in not only their benefits toward "camping", "trail activities", "wildlife viewing" but the other typologies, such as "flood control" in hydrological ecosystem services, "healthy community lifestyle" in community and cultural ecosystem services, and "maintain rural character" in working lands ecosystem services. This was a common occurrence among the criteria and served to illustrate the multifunctionality of landscape typologies and classifications within the region.

The totals (vertical axis) provided the additive values of the overall ecosystem services in the region, as distinguished by the landscape typologies identified. The last row of Scheme 2 shows these results, with 34.5 the highest score and 5.5 the lowest, out of a possible 41 .

Next, the highest value landscape classifications with associated ecosystem services (horizontal axis) was 36 and the lowest value was 1, out of a possible total of 36 . Normalized or standardized values were then produced for each landscape classification and scaled to a range of 0 to 100 . The last columns of Scheme 2 show the results for each landscape classification where each of the ecosystem service weighting values was totaled then normalized to $100 \%$ for easier comprehension and relational context. These were interim steps only and a statistical analysis or discussion of the results was not required. This matrix served to structure data collection, data organization, and MCE relationships, in order to better integrate and visualize the data within the applications of Step 3 and Step 4 . The final matrix of Scheme 2 was approved by the TAC.

\section{Step 3: GIS Data Visualization}

Scheme 2's normalized value ranking, or total weighting value, provided the data to populate each GIS data layer, the landscape classifications, and their polygon attributes. The GIS polygon data was then processed through the GIS tool "Union". Here, all GIS layers $(n=41)$ that were originally separate were merged to one layer. This resulted in over 800,000 polygons. The criteria or individual values for each landscape typology (e.g., Hydrological network-reservoirs $=3.4 \%$ normalized value, Scheme 2 ) were summed to create a single aggregate value for each new polygon created through the "Union" tool, with a maximum value of $46.7 \%$. The Union tool in GIS combined different data layers and is considered a type of multicriteria weighted overlay analysis in this application. Where the landscape classification polygons intersected, their values were added together. In this study, the higher the \% value of a given polygon, the higher number of ecosystem services that were attached to it.

These GIS dataset values were then categorically ordered using the Jenks Natural Breaks Classification (JNBC) within ArcMap [80]. This method served to "break" or "cluster" the dataset into a hierarchical ranking system within an optimum range. Though other methods exist, such as nested means classification [81] and linear scaling, the JNBC was employed for two reasons. First, because the polygons were weighted, categorization responded to the weighting as opposed to simple, equal interval breaks. Secondly, this method reduced the variance within polygon value ranges and maximized the variance between them, thereby providing a "goodness of variance fit". This resulted in four total 
"optimum breaks" or polygon value ranges from 0 to $13.6 ; 13.6+$ to $18.4 ; 18.4+$ to 23.9 ; and $23.9+$ to 46.7 . These breaks were labeled as low, medium, high, and very high. There were no scores over 46.7 , as this was the most any single polygon had out of a possible total of 100. The classes were based on natural groupings inherent in the data. ArcMap identified the break points by picking the class breaks that best group similar values and maximize the differences between classes, and ranges are set where there are relatively big jumps in the data values. This categorical ordering provided the summarized values to the spatial data, which was added to the GIS datasets in Step 4.

\section{Step 4: Green Infrastructure Mapping}

This step provided the final data classification and its visualization in map form. Step 3's hierarchical ranges were directly correlated to the green infrastructure network spatial classifications of cores, hubs, and corridors [40]. Cores are highly functional lands that provide multiple ecosystem services; they are comprised of high quality "patches" or areas of intact landscapes such as old growth forests or unmitigated wetlands. Hubs are landscapes that support core functionality; they do this by providing an arrangement of supporting, semi-intact lands throughout the region, such as timber forests and woodlands between housing developments. Hubs are not always in immediate proximity or "connected" to core areas, but they enhance core and GI landscape functionality. Corridors are essential to the composition of a regional GI landscape; they provide a physical means to connect GI typologies and include streams, urban forests, hedgerows, and even bike lanes.

This classification scheme has been employed in other green infrastructure mapping procedures, e.g., [82,83]. The GI classifications provided the overall spatial framework for mapping the landscape through their polygon values. Specifically, the very high and high values, ranging from 18.4 to 46.7, were represented as core areas. The medium value ranges, from 13.6 to 18.4 , as hub areas. The low values, 0 to 13.6, were not assigned any spatial entity and were removed from the dataset, as these had minimal ecosystem service value to the landscape typologies. Corridor determination was specific to each GI typology.

The GI classifications of core, hub, and corridor were then reviewed comprehensively and contextually so that additional ecosystem service criteria not present within the prior steps could be accounted for. This included a qualitative reranking of the GI classification as a means to value add or value reduce specific polygon data within the dataset. Specific landscape-ecology criteria regarding minimum thresholds, such as size, density, species composition, and proximity, as well as exclusion factors such as invasive species or impairments, were reviewed. For example, wetland polygons were required to be at least $50 \mathrm{~m}$ in diameter to have GI core classification, a measure of hydrological function. If these wetland polygons did not meet this criterion, they were reclassified as hubs. Similarly, areas of environmental concern that did not result in the highest ranking of core designation were assigned the core rank. Exclusion factors were also reflected in the spatial mapping; polygons that included invasive species were reassigned a lower value ranking. This information was determined through the comprehensive review of the stakeholder's strategic plans, planning documents, and reports in Table S1, as well as GIS metadata. Stakeholder experts and scientists, TAC members, and authors of these documents were consulted specifically to review and approve the criteria. Table S4 provides the full GI criteria review process and explanation for core, hub and corridor determination and, if applicable, redesignation, including all inclusion and exclusion factors, as well as their specific modeling procedure and polygon shapefile names.

It is noted that this reclassification would not effectively achieve this study's goals through the simple adjustment or numerical reweighting in Step 2; this type of information and the relationships they impact are simply not present within that data. This qualitative review was an important step of ensuring both accuracy to the spatial data and their values, to ensure that they were capable of providing those ecosystem services and, overall, meaningful results to the study. This green infrastructure (GI) hierarchical framework for each landscape classification and typology dataset was then mapped. These datasets, including shapefiles and raster data, were geoprocessed within ArcGIS 10.6. 


\section{Results}

The simple statistic results are presented overall and specific to each landscape typology, for clarity, in the last rows of Scheme 2. These rows summarize the specific ecosystem services totals associated to the landscape typologies. This is simply an aggregate total of the weighted ecosystem service ranking, no other statistical analyses were completed or required to meet the goals of this study.

\subsection{Ecosystem Services}

Descriptive statistics shown in the last three columns of Scheme 2 illustrate the total weighted ecosystem service rankings out of a total of 36 for each landscape classification, their normalized percentage value, and their total value percentage. The total values of all landscape typologies were 798.5. When the total landscape typology weighting was divided by this total value, normalized values were produced. Normalized values serve to simply aggregate criteria for comparison and assists in multicriteria decision making.

The three highest ranked ecosystem services were economic health $(n=34.5)$ within the community and cultural typology, economic support $(n=33.5)$ within the working lands typology, and both air quality $(n=31)$ within the ecological typology and sense of community $(n=31)$ within the community and cultural typology. The lowest ranked were forest products $(n=5.5)$ within the working lands typology and paddling $(n=14)$ within the recreation typology. These totals simply summarized those ecosystem services identified within the region's landscape typologies.

\subsection{Green Infrastructure Typologies and Landscape Classifications}

The three highest percentage landscape typologies within the matrix were hydrological $(31.5 \%)$, ecological $(30.6 \%)$, and community and cultural (15.0\%). These percentages simply show which of the region's landscape classifications were weighted within its landscape typology and considered to have a relationship to many varied ecosystem services.

The top three highest ranked ecosystem producing landscape classifications were found within the ecological landscape typology: wildlife habitat $(n=36)$, at-risk wildlife habitat $(n=35.5)$, and conservation action areas $(n=35.5)$. These rankings mean that more ecosystem service relationships existed, direct or indirect (i.e., ' 1 ' or ' $0.5^{\prime}$ ), within these landscapes. The lowest ranked were landslide areas $(n=5)$ within the working lands typology and paddling $(n=14)$ within the recreation typology. Overall, the highest ranked percentage of the landscape typologies and their associated classifications providing ecosystem services were $31.5 \%$ for hydrological $(n=251.5), 30.6 \%$ for ecological $(n=244), 15 \%$ for community and cultural $(n=119.5), 12.1 \%$ for recreational $(n=96.5)$, and $10.9 \%$ for working lands $(n=87)$. This simply summarized the total number of the five landscape typologies considered to have a relationship to ecosystem services.

\subsection{Green Infrastructure Mapping Results}

The five GI network maps illustrate the Wasatch Front's green infrastructure landscape resources, all of which contribute to diverse ecosystem services. As shown, each GI landscape typology contributes to the ecosystem services of others, thereby illustrating a more comprehensive evaluation of the regions landscape and multifunctional benefits. Though all GI is considered "ecological", this study's use of five typologies serve to clarify and distinguish the overlapping management goals of the region's landscape. The completed GI maps for each of the five landscape typologies are presented, in order to illustrate the mapping process outcome and data interpretation. It must be noted that these maps are not scientific implementation tools but regional GI spatial information generated through this study's ecosystem service MCE identification. Scheme 3 provides the results of a simple statistical analysis of the GI typologies. Figures 2-6 provide the mapping results. 


\begin{tabular}{|c|c|c|c|c|c|c|}
\hline & Number & $\begin{array}{l}\text { Minimum } \\
\text { size } \\
\text { (acres) }\end{array}$ & \begin{tabular}{|c|} 
Maximum \\
size \\
(acres)
\end{tabular} & $\begin{array}{l}\text { Mean } \\
\text { size } \\
\text { (acres) }\end{array}$ & $\begin{array}{c}\text { Regional } \\
\text { Calculations } \\
\text { (acres) }\end{array}$ & $\begin{array}{c}\% \text { Project } \\
\text { Area }\end{array}$ \\
\hline \multicolumn{7}{|l|}{ Ecological GI Network } \\
\hline Cores & 6,299 & 0.010 & 605,162 & 372 & $2,344,377$ & $37 \%$ \\
\hline Hubs & 5,314 & 0.001 & 89,091 & 117 & 620,118 & $10 \%$ \\
\hline Total & & & & & $2,964,495$ & $47 \%$ \\
\hline Existing Corridors (Miles) & & & & & 495 & \\
\hline \multicolumn{7}{|c|}{ Hydrological GI Network } \\
\hline Cores & 14,004 & 0.020 & 706,790 & 74 & $1,030,122$ & $16 \%$ \\
\hline Hubs & 29,948 & 0.000 & $1,801,970$ & 83 & $2,494,221$ & $39 \%$ \\
\hline Totals & & & & & $3,524,343$ & $55 \%$ \\
\hline \multicolumn{7}{|c|}{ Recreational GI Network } \\
\hline Cores & 20,179 & 0.003 & $2,038,850$ & 146 & $2,951,732$ & $46 \%$ \\
\hline Hubs & 7,671 & 0.010 & $1,177,970$ & 156 & $1,200,231$ & $19 \%$ \\
\hline Totals & & & & & $4,151,963$ & $65 \%$ \\
\hline Existing Corridors (Miles) & & & & & 971 & \\
\hline \multicolumn{7}{|c|}{ Working Lands GI Network } \\
\hline Cores & 22,232 & 0.008 & 123,659 & 71 & $1,584,806$ & $25 \%$ \\
\hline Hubs & 5,164 & 0.003 & 686,693 & 187 & 967,409 & $15 \%$ \\
\hline Totals & & & & & $2,552,215$ & $40 \%$ \\
\hline Existing Corridors (Miles) & & & & & 2,072 & \\
\hline \multicolumn{7}{|l|}{ Community GI Network } \\
\hline Cores & 1,624 & 0.100 & 480,145 & 491 & 600,636 & $9 \%$ \\
\hline Hubs & 253 & 0.200 & $3,694,750$ & 11,345 & $3,749,151$ & $59 \%$ \\
\hline Totals & & & & & $4,349,787$ & $68 \%$ \\
\hline Existing Corridors (Miles) & & & & & 7,505 & \\
\hline
\end{tabular}

Scheme 3. Green infrastructure typology statistical analysis results.

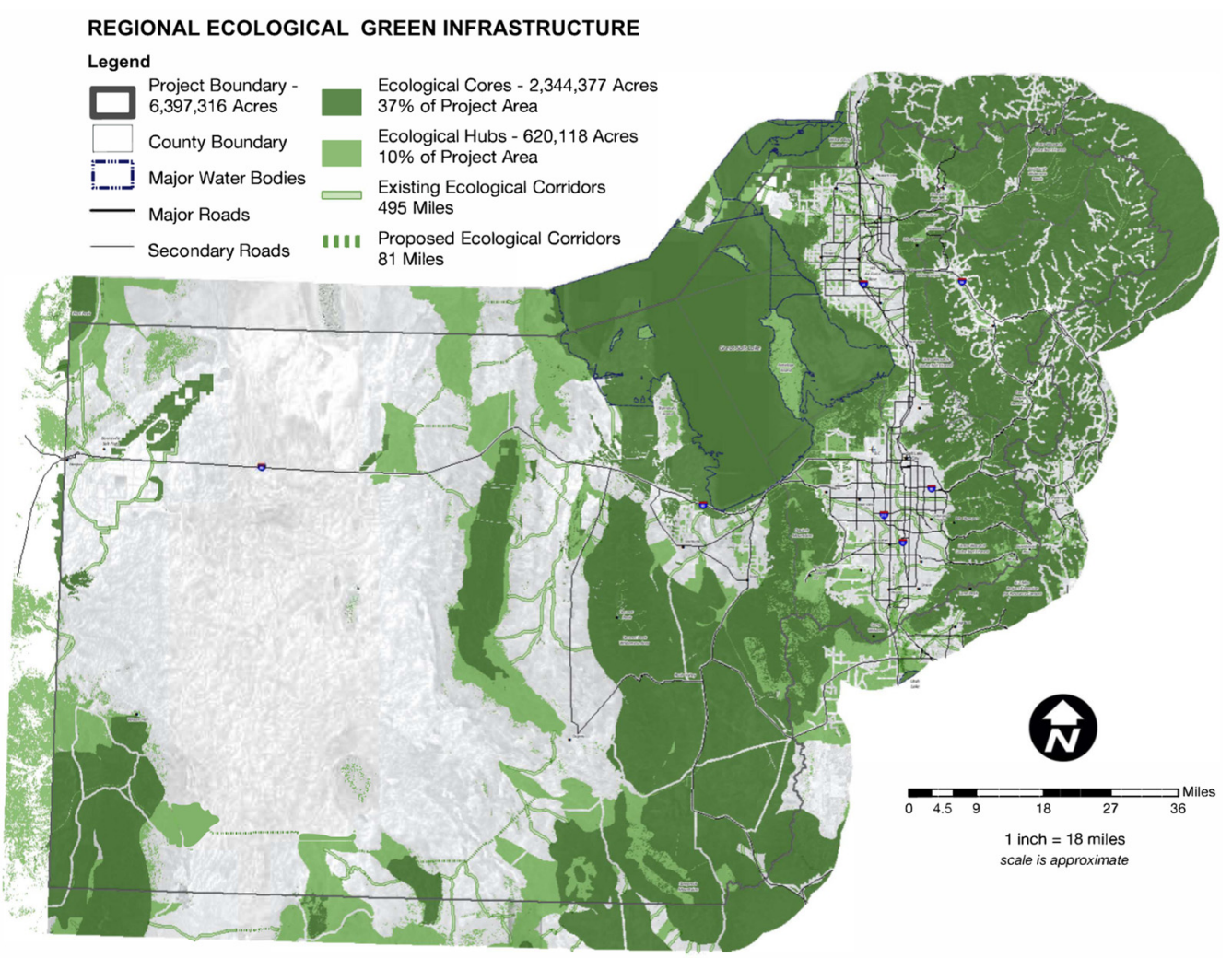

Figure 2. Ecological Green Infrastructure Map. $47 \%$ of the project area, or nearly 3 million acres, is comprised of ecological GI cores and hubs with 495 miles of existing corridors. 


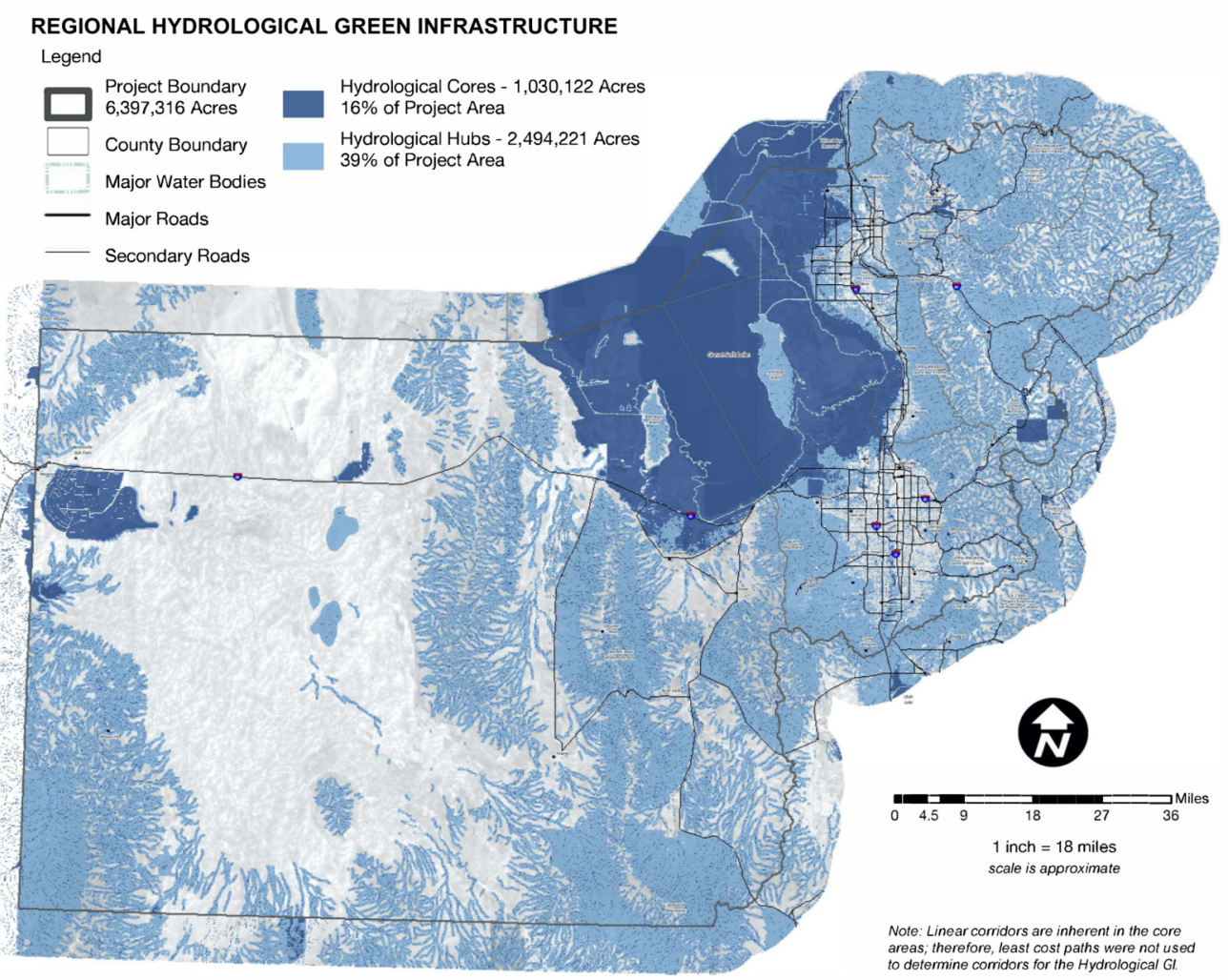

Figure 3. Hydrological Green Infrastructure Map. 55\% of the entire project area, over 3.5 million acres, is comprised of hydrological GI cores and hubs.

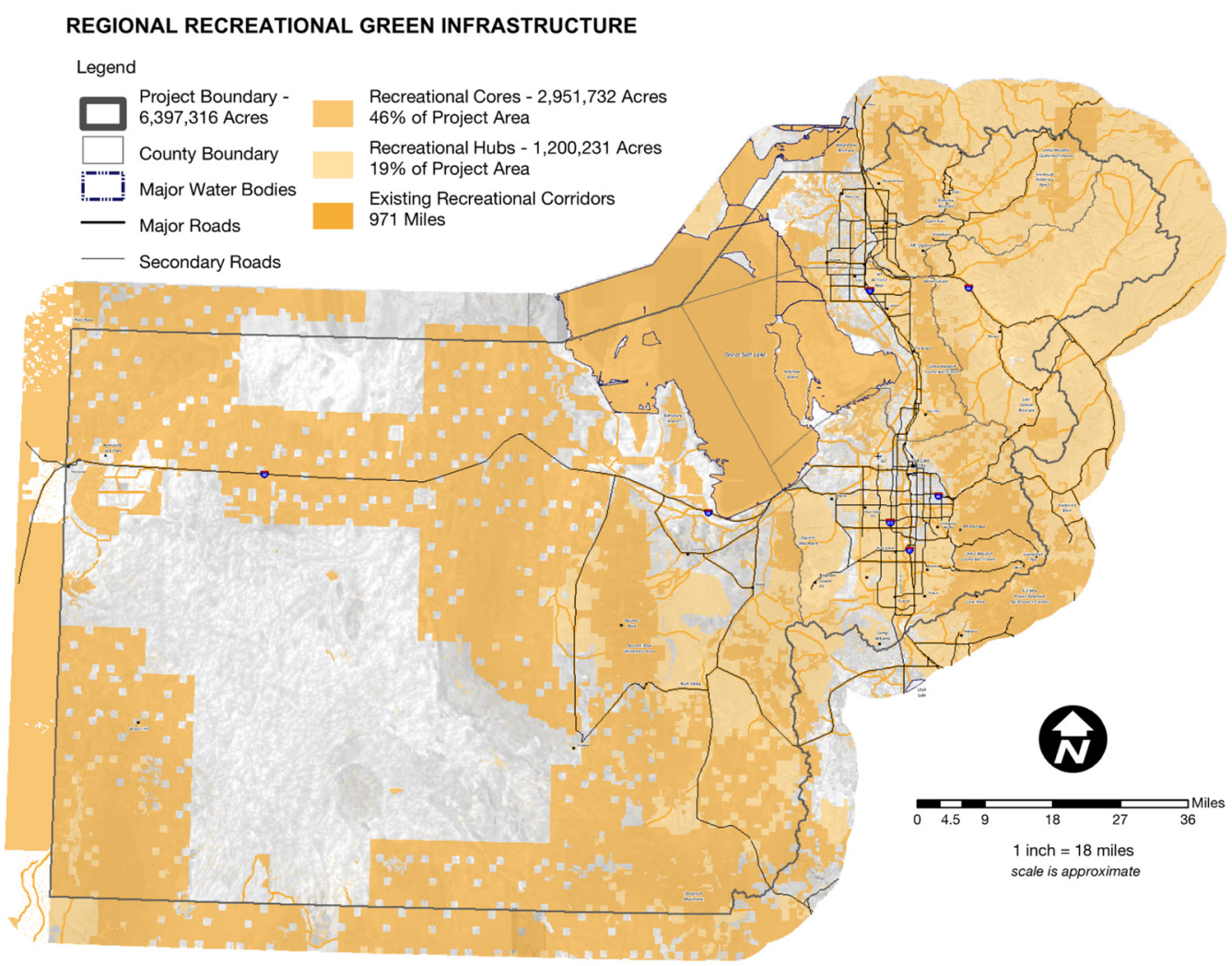

Figure 4. Recreational Green Infrastructure Map. 65\% of the project area, over 4 million acres, is comprised of recreational GI cores and hubs, with 971 miles of corridors. 


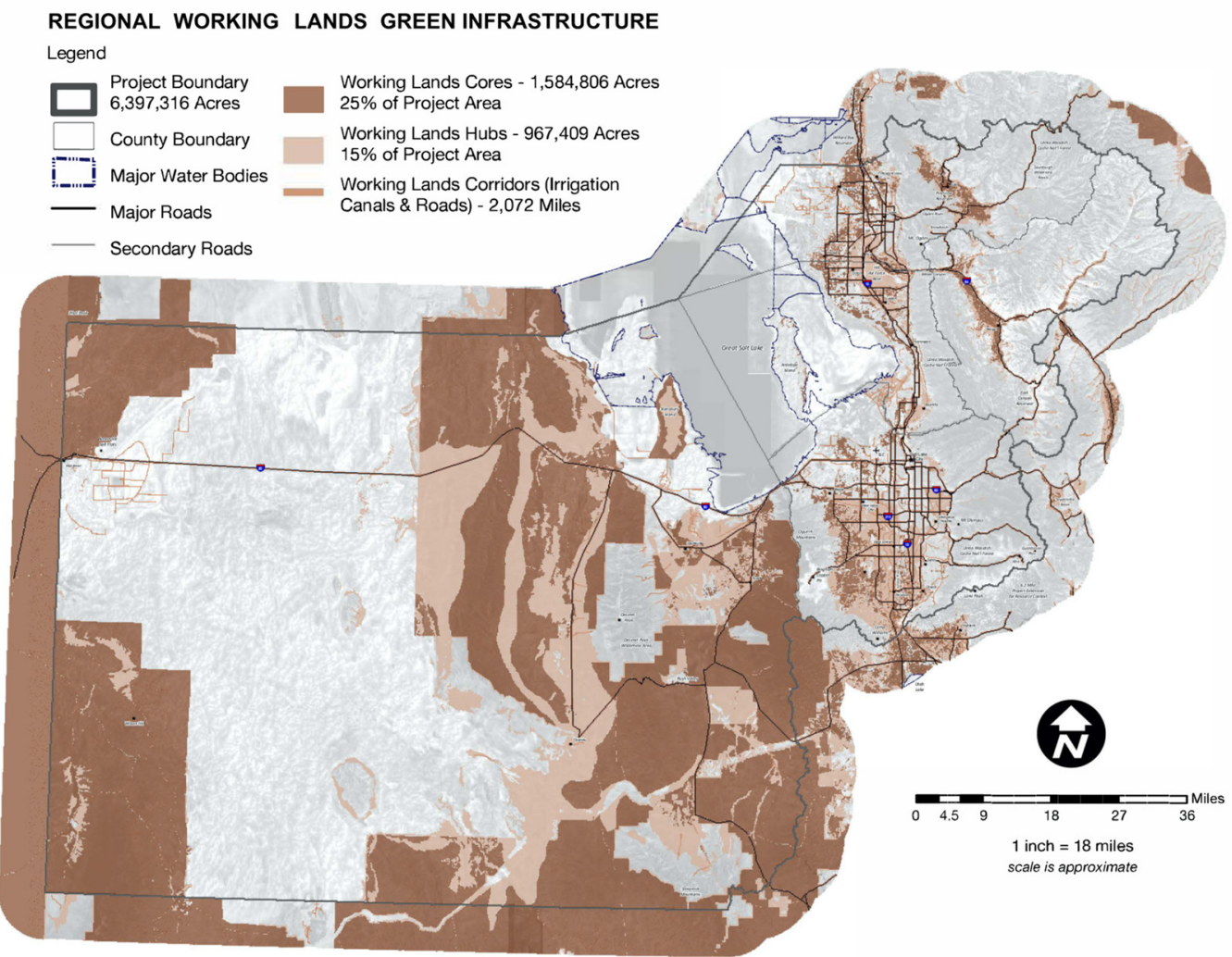

Figure 5. Working Lands Green Infrastructure Map. 40\% of the project area, over 2.5 million acres, is comprised of working lands GI cores and hubs with 2072 miles of corridors.

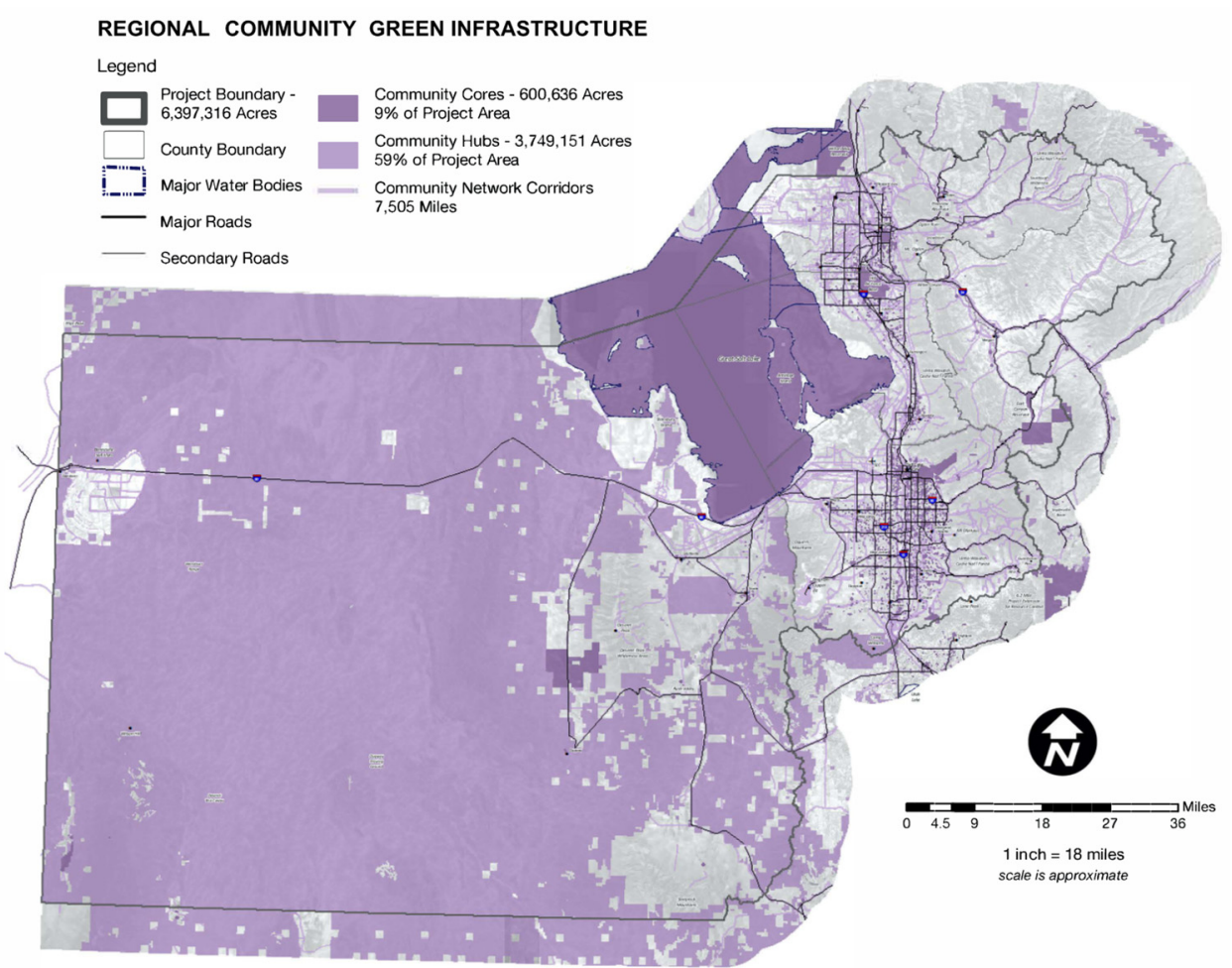

Figure 6. Community and Cultural Green Infrastructure Map. 68\% of the project area, over 4 million acres, is comprised of community GI cores and hubs with 7505 miles of corridors. 


\section{Discussion}

The purpose of this case study was to identify the green infrastructure of the region which provided a set of integrated ecosystem services. The GI maps illustrated the Wasatch Front's landscape resources and represented areas of highest ecosystem service function and value across multiple benefit frameworks-not just one, such as hydrological water quality. As shown, each identified GI landscape contributed to the ecosystem services of other landscape typologies. These results illustrated a more comprehensive evaluation of the region and its multifunctional benefits, which also served to clarify the landscape's existing structure, function, and value.

Though the hydrological typology and ecology typology make up nearly $62 \%$ of the region's total ecosystem producing landscape (Scheme 2), this result does not reflect the region's total landscape area (Figures 2 and 3, Scheme 3). The largest sized green infrastructure landscape, including cores and hubs, was the community typology $(4,349,787 \mathrm{ac})$ and recreational landscape $(4,151,963 \mathrm{ac})$. This comparison does not necessarily represent a disconnect between landscape and ecosystem services within the region, just an aggregate total. To clarify, the landscape with the largest total landscape area of cores was the recreational typology $(2,951,732 \mathrm{ac})$, as well as the largest single sized core $(2,038,850 \mathrm{ac})$. The landscape with the largest total landscape area of hubs was the community typology $(3,749,151 \mathrm{ac})$, as well as the largest single sized core $(3,694,750 \mathrm{ac})$. These spatial results must be interpreted within the overall landscape context and objectives. Thus, these two spatially large GI typologies (e.g., community and recreational) do not represent the most wide and diverse ecosystem producing typologies (e.g., hydrological and ecological).

Furthermore, the results in Scheme 3 provide a better understanding of the physical network of cores and hubs within each typology. Literature supports a "balanced" system of cores and hubs, as each serve to enhance and support the multifunctional ES benefits of one another [50]. Whereas the community GI includes $68 \%$ of the total regional landscape, $59 \%$ of that is within the core delineation and $9 \%$ hub. Alternatively, the hydrological GI has a more balanced delineation with $16 \%$ cores and 39\% hubs. Though the community GI seems skewed to mostly hub rankings, this GI does provide the largest distance of total corridors for the region, with 7505 miles, though most of these are single function, such as bike lanes and designated bus routes, as opposed to the streams and hiking trails found within the other GI typologies.

Results showed it was only the wildlife habitat landscape classification that received a " 1 " weighted ranking for every ecosystem service $(n=36 / 36)$. This signifies that, as a region, these landscapes and the management practices of the many varied stakeholders encompassing the many wildlife habitats in the region have a significant impact on the delivery of a wide array of ecosystem services, including hydrological, recreational, working lands, and community benefits. For example, nearly 500 miles of existing ecological network corridors were calculated (See Figure 2 and Table S4). Eighty percent $(80 \%)$ of the native wildlife in the Wasatch Front relies upon wetlands and riparian ecosystems for survival, yet these ecosystems comprise only $2 \%$ of the existing land cover [84]. Wetland areas were already factored into the ecological core designation. Therefore, it was determined that existing corridors based on riparian land cover types would be beneficial to most wildlife species. The existing corridors identified in the Ecological GI Network Map are useful to land planners and wildlife managers, as they represent the most efficient riparian connections between core and hub areas. These serve as potential priority areas for enhancement and expansion, as well as the promotion of biodiversity.

\subsection{Challenges and Opportunities for the Integration of Ecosystems Services and Green Infrastructure in Policy and Planning}

Though there are many questions that may develop when looking at the GI maps, the full criteria and polygon delineation is provided within the Supplementary Information for the interested reader. The methods proposed in this study have applications across multiple disciplines and support efforts towards standardized ES assessment and spatial mapping; 
they can be modified and applied in other MCE analyses or to develop "new" relationship based criteria. Though this study applied a broad set of ecological based and human based ES ranking of "direct" or "indirect" across multiple landscape typologies, the relationship between landscape and ES exists at multiple contexts and scales which are to be further developed. The objective of the classification and ranking within the multifunctional green infrastructure strategy for the Wasatch Front was to develop a systematic process for making decisions about land use planning and sustainable development. The GI landscapes are multicontextual and their development expressed the physical and functional relations of GI and ES within the regional landscape.

Ecosystem service mapping is a rapidly evolving field and this study exhibits limitations in its ES assessment. As a working map and weighting approach, further data can be integrated or even developed to fit within the GI framework. For example, this study does not consider ecosystem service supply-demand in its mapping, nor utilize modeling to formulate GI impacts. This study's ranking included the terms "direct" and "indirect" benefits. ES demand, as a mapping and sustainable planning approach, does consider the provisioning, regulating and supply components of ES. However, the demand for ES is embedded in the complex socio-ecological system relationship with other components [85] and quantification is difficult to agree upon.

The scientific evidence for the MCE ES values of Scheme 2 is not fully explained in this paper due to space limitations, but supported within Table S4. These valuations are, to the best degree possible, synthesized from the region's various scientists (e.g., hydrologistecologist-recreationist, all valuing the same landscape classification such as "wetland pond") and not modelled or quantified collectively. This is a future endeavor that can be completed by the various stakeholders regionally or on a parcel basis. Additionally, different value scales and weighting methods can be applied to refine the value matrix, such as factor analysis and principal component analysis (PCA). This study used but one weighting, organized around specific and inclusive criteria.

This study presented an approach to analysis; other approaches, such as overlay mapping of stakeholders or agency management lands, may provide interrelated knowledge to identify areas of potential collaboration, for example. Though this study's spatial mapping was completed through a type of multicriteria weighted overlay, exploring unweighted overlays and other spatial approaches within suitability analysis, value reclassification/reallocation, vulnerability assessment, aggregated mapping, and others [86] may be utilized.

As with most mapping, this methodology towards ES identification and spatial visualization can be modified and updated to suit varied landscape contexts. This framework exhibited distinct stakeholder cooperation and communication and ultimately enhanced the legitimation of the criteria ranking. This study's multifunctional based ES GI development methodology can be used many ways and applied by a number of agencies and organizations. For example, both MCE criteria and GI map generation serve to clarify and enhance planning strategies at regional and local scales as well as to stimulate communication and coordination between stakeholders. In this regard, the GI map becomes a type of collaborative decision-making tool, combining criteria based geographical data into spatial based rankings.

As a strategic planning tool, this study's framework assists various stakeholders with overlapping, divergent and even conflicting interests. It also allows them to better coordinate efforts and arrive at mutually beneficial solutions to existing and potential concerns. Specifically, it serves to identify potential restoration projects, acquisitions, conservation initiatives, and other land planning and management activities such as those related to water quality and quantity or habitat. It can clarify priority areas for enhancement, expansion, and connectivity for community facilities, recreation, agriculture, and forests. This study's comprehensive framework helps proactively identify action areas; it places the various landscapes within a larger context that can help policy makers better understand the implications of every action. It is a useful tool for transportation planners, community 
planners, sociologists, economic analysts, historic preservationists, and others to assess livable community conditions and connectivity in order to identify those areas where they might be improved.

This study's generation of maps was a key output to illustrate multifunctionality across stakeholder interests. These maps can be used as standalone information or integrated with other data and maps. Map overlays are examples of how additional data can be added to the foundation of the GI maps to arrive at new tools relevant to specific decision making. For example, overlay mapping of the typologies can be applied in a number of ways. Areas of overlap illustrate where potential impacts, positive or negative, could occur. In this study, areas of overlap between the recreational and hydrological GI landscapes illustrate where water quality may sustain impacts from recreational usage such as hiking and biking. Thus, trails along streams or drainages would require design and management strategies to minimize adverse impacts to water quality.

Other examples of maps with useful applications that can be generated include:

- Areas of overlap between the community GI and the recreational GI to illustrate areas where accessibility may be lacking;

- Areas of overlap between the working land GI and ecological GI to illustrate zones where suitable agricultural and grazing practices should be employed to simultaneously support working lands productivity and maintain and enhance ecosystem health and integrity.

Furthermore, additional and specific maps may be applied to this study's GI maps:

- Soils maps, particularly those within developed areas (not agricultural zones) to illustrate areas that may be appropriate for urban farming or urban forest expansion;

- Areas of overlap with land ownership, particularly private lands, where specific stewardship incentives can be prioritized;

- Areas of overlap between the ecological and hydrological GI and natural hazards to illustrate areas that should be prioritized for conservation due to a lack of suitability for development.

This study did not provide an overlap map of all five GI maps which could identify regional summarized core and hub rankings (e.g., 1x-5x overlap). These would serve to simply identify those highest ranking GI landscape classifications, or most multifunctional within this framework, which may or may not have impact on the other GI typologies and their ecosystem services.

Perhaps most significant is that such overlap maps highlight areas that may require collaboration and cooperation between the Wasatch Front stakeholders. Such maps can be used as a resource to encourage these actions and other appropriate land planning strategies. No single planning or management strategy will be appropriate for all resources. The incorporation of site specific data will be required to identify the most appropriate strategies for each site and landscape typology.

As landscapes change over time, these maps can be updated and analyzed to monitor progress and success. Site specific data can be added and these maps thus become a useful tool in strategic planning, adaptive management, and decision making. Overall, collaborative stewardship can occur between the stakeholders in order that the varied landscapes can continue to provide multiple and diverse ecosystem services to the region.

\subsection{Innovative Ecosystem Services Mapping within a Green Infrastructure Approach for Sustainable Development}

Ecosystem service spatial modelling is a key component to integrated assessments which support management and policy toward sustainable development. This case study illustrated a framework for linking landscapes to ecosystem services. ES mapping makes the benefits of landscapes spatially explicit. This study presented an integrated approach, combining landscape typologies and comprehensive ecosystem services within a matrix to support combinations of multifunctional services and benefits. 
Though the ES listed in Scheme 2 as listed are difficult to quantify and measure as a scientific based ecosystem service indicator, for this study, as a regional plan of diverse stakeholders and land planners and managers (i.e., few scientists), this approach of generalized ES indicators was useful in engaging discussion and awareness of their overlapping interests. Sustainability can have many different meanings [87], most green infrastructure and ecological definitions highlight the desire to maintain resilience, integrity, and the capacity for renewal in environmental and social systems by meeting a diverse range of interconnected environmental, social, and economic goals [88,89]. This study's framework demonstrated the reciprocal relationship between natural and social systems, but economic considerations must be included in this model to promote dialogue regarding sustainability. Most sustainability models illustrate a positive, balanced relationship between the environment, society, and the economy, and this paper's green infrastructure framework provides an ideal foundation for advancing the sustainability dialogue.

This study's green infrastructure approach to sustainable planning and GIS mapping was asset based and multifunctional, it identified which landscape types provided which specific benefits or ecosystem services across multiple landscape features or classifications. This multicriteria strategy builds upon previous green infrastructure and environmental planning approaches but also illustrates a means to include human based features of the landscape. For example, this framework included a distinctly anthropocentric mapCommunity and Cultural GI. This map's grouping of cores, hubs, and corridors focused distinctly on sociocultural ecosystem services such as economic health, heritage, and healthy lifestyles. Interestingly, economic health was the highest ranking ecosystem service in the region, encompassing almost every landscape typology.

However, complex socioecological systems and landscapes are unpredictable and problematic to manage due to multiple interaction factors [90,91]. A recent term, socialecological-technical systems (SETS) better addresses change and adaptive management [92], particularly as technology plays an ever increasing role in ecosystem functionality and resilience in urbanizing landscapes [93].

This study demonstrated a multicriteria analysis to map green infrastructure regions based on comprehensive ecosystem services according to combined ecological, social and economic criteria to the best degree possible within its approach and framework. Other frameworks exist and offer insight to ES and MCE; for instance, this methodology does not account for ES supply and demand, nor the many variables found within their functional interrelations and offer areas of further research. Though not referenced directly, the basic ES frameworks of the MEA and CICES were foundational to this study's MCE. For instance, though the terms "provisioning, regulating, and supporting services" are not explicitly stated within the MCE's matrix, these are documented within the weighting criteria of Table S4. Overall, this study's MCE within the GI framework does effectively synthesize qualitative and quantitative information on ecosystem services.

Other areas of future study include clarifying economic ES across diverse stakeholders and their relationship to spatial landscapes. A better understanding of the components and the interactions of cultural and community GI is needed. Sustainable development requires public and private input, multiorganizational involvement, and interagency cooperation. Within the context of urbanization and other human impacts, these GI maps identify highly functional landscapes for which collaborative strategic planning efforts can direct urban development away from green infrastructure lands, thereby protecting ecosystem service generating landscapes. A standardized ES list does not exist, and may never, but the GI framework provides a means to view ES in multiple contexts and creates pathways to overlooked ES identification.

\section{Conclusions}

The need for a sustainable approach to landscape planning and management is understood across urbanizing regions of the globe, requiring new techniques for spatial analysis and decision making. The spatial dimensions of sustainability engage processes and in- 
terconnections between different land uses and systems at different scales. Ecosystem service mapping can be a powerful tool for understanding the characteristics of green infrastructure multifunctionality by enabling the identification of those landscape components. In doing so, ES mapping serves to effectively analyze interrelations among their varied roles and functions. Green infrastructure provides an interconnected landscape framework to classifying and mapping landscapes. GI mapping is the critical first phase to maintaining landscapes' ability to perform different functions and manage the system of multifunctional ecosystem services. Multicriteria frameworks bridge disciplines and stakeholders, and they encourage sustainability indicator development across multiple landscape contexts and governance levels. However, further integration is recommended. Green infrastructural spatial mapping illustrates the relative amount of ecosystem services provided within different landscape types. It also supports sustainable planning, management, and policy, as it ensures the inclusion of information relevant to decision makers at different levels. GI ES mapping allows for interdisciplinary interagency comparison, evaluation, and collaboration. Fore more information, please refer to Supplementary Materials Tables S1-S4.

This paper contributes to a better understanding of how to synthesize data and approaches required for sustainable planning. In testing this framework, this study concludes that applying the concepts of green infrastructure to illustrate ecosystem services is a valuable approach to addressing multifunctional landscapes and the myriad of stakeholders and overlapping planning goals, particularly in urban and urbanizing regions where complex landscapes predominate. By integrating spatial based MCE into the management framework, stakeholders and managers will increase their ability to clarify the decision context, quantify, and anticipate beneficial impacts on ecological and human wellbeing, and gain insight into the long term efficacy of sustainable planning.

Supplementary Materials: The following supporting information can be downloaded at: https: / /www.mdpi.com/article/10.3390/su14020825/s1, Table S1: Technical advisory committee members; Table S2: Documents reviewed for landscape planning goal development; Table S3: GIS dataset source and name list; Table S4: Green infrastructure network criteria and GIS modeling.

Funding: This work was supported by the Wasatch Front Regional Council.

Institutional Review Board Statement: Not applicable.

Informed Consent Statement: Not applicable.

Data Availability Statement: The data presented in this study are available in the article or supplementary materials.

Acknowledgments: The author wishes to acknowledge Sumner Swaner and Lindsay Winkler for their assistance in this study.

Conflicts of Interest: The author declare no conflict of interest.
Abbreviations
ES Ecosystem services
GI Green infrastructure
MCE Multicriteria evaluation
TAC Technical advisory committee

\section{References}

1. Scholes, R.J.; Reyers, B.; Biggs, R.; Spierenburg, M.J.; Duriappah, A. Multi-scale and cross-scale assessments of social-ecological systems and their ecosystem services. Curr. Opin. Environ. Sustain. 2013, 5, 16-25. [CrossRef]

2. Ritchie, H.; Roser, M. Urbanization. Available online: https:// ourworldindata.org/ urbanization (accessed on 10 December 2018).

3. UN-Habitat. World Cities Report 2016: Urbanization and Development: Emerging Futures. Available online: https://unhabitat. org/world-cities-report (accessed on 10 December 2016). 
4. Alberti, M. Maintaining ecological integrity and sustaining ecosystem function in urban areas. Curr. Opin. Environ. Sustain. 2010, 2, 178-184. [CrossRef]

5. $\quad$ Pauleit, S.; Hansen, R.; Rall, E.L.; Zölch, T.; Andersson, E.; Luz, A.C.; Szaraz, L.; Tosics, I.; Vierikko, K. Urban landscapes and green infrastructure. In Oxford Research Encyclopedia of Environmental Science; Oxford University Press: Oxford, UK, 2017.

6. Qian, Y.; Zhou, W.; Pickett, S.T.; Yu, W.; Xiong, D.; Wang, W.; Jing, C. Integrating structure and function: Mapping the hierarchical spatial heterogeneity of urban landscapes. Ecol. Process. 2020, 9, 1-11.

7. Swyngedouw, E.; Heynen, N. Urban Political Ecology, Justice and the Politics of Scale. Antipode. 2003, 35, 898-918.

8. De Groot, R.S.; Wilson, M.A.; Boumans, R.M. A typology for the classification, description and valuation of ecosystem functions, goods and services. Ecol. Econ. 2002, 41, 393-408. [CrossRef]

9. Reid, W.V.; Mooney, H.A.; Cropper, A.; Capistrano, D.; Carpenter, S.R.; Chopra, K.; Dasgupta, P.; Dietz, T.; Duraiappah, A.K.; Hassan, R.; et al. Ecosystems and Human Well-Being-Synthesis: A Report of the Millennium Ecosystem Assessment; Island Press: Washington, DC, USA, 2005.

10. Schröter, M.; van der Zanden, E.; Alexander, P.; van Oudenhoven Remme, R.; Serna Chavez, H.; de Groot, R.; Opdam, P. Ecosystem services as a contested concept: A synthesis of critique and counter arguments. Conserv. Lett. 2014, 7, 514-523. [CrossRef]

11. De Groot, R.; Hein, L. Concept and valuation of landscape functions at different scales. In Multifunctional Land Use; Springer: Berlin/Heidelberg, Germany, 2007; pp. 15-36.

12. Palomo, I.; Felipe-Lucia, M.R.; Bennett, E.M.; Martín-López, B.; Pascual, U. Disentangling the pathways and effects of ecosystem service co-production. Adv. Ecol. Res. 2016, 54, 245-283. [CrossRef]

13. Schröter, M.; Crouzat, E.; Hölting, L.; Massenberg, J.; Rode, J.; Hanisch, M.; Kabisch, N.; Palliwoda, J.; Priess, J.A.; Seppelt, R.; et al Assumptions in ecosystem service assessments: Increasing transparency for conservation. Ambio 2021, 50, 289-300. [CrossRef]

14. McDonald, R.I. Ecosystem service demand and supply along the urban-to-rural gradient. J. Conserv. Plan. 2009, 5, 1-14. [CrossRef]

15. Hölting, L.; Beckmann, M.; Volk, M.; Cord, A.F. Multifunctionality assessments-More than assessing multiple ecosystem functions and services? A quantitative literature review. Ecol. Indic. 2019, 103, 226-235.

16. Gebre, T.; Gebremedhin, B. The mutual benefits of promoting rural-urban interdependence through linked ecosystem services. Glob. Ecol. Conserv. 2019, 20, e00707. [CrossRef]

17. Pagella, T.F.; Sinclair, F.L. Development and use of a typology of mapping tools to assess their fitness for supporting management of ecosystem service provision. Landsc. Ecol. 2014, 29, 383-399.

18. Tardieu, L. The need for integrated spatial assessments in ecosystem service mapping. Rev. Agric. Food Environ. Stud. 2017, 98, 173-200.

19. Anna, K.; Jaan-Henrik, K.; Jakub, K.; Dagmar, H. Ecosystem services in urban land use. Services 2016, 22, 204-212. [CrossRef]

20. Sterling, E.; Ticktin, T.; Morgan, T.K.K.; Cullman, G.; Alvira, D.; Andrade, P.; Bergamini, N.; Betley, E.; Burrows, K.; Caillon, S.; et al. Culturally grounded indicators of resilience in social-ecological systems. Environ. Soc. 2017, 8, 63-95. [CrossRef]

21. Fagerholm, N.; Martín-López, B.; Torralba, M.; Oteros-Rozas, E.; Lechner, A.M.; Bieling, C.; Stahl Olafsson, A.; Albert, C.; Raymond, C.M.; Garcia-Martin, M.; et al. Perceived contributions of multifunctional landscapes to human well-being: Evidence from 13 European sites. People Nat. 2020, 2, 217-234. [CrossRef]

22. $\mathrm{Wu}, \mathrm{J}$. Landscape sustainability science: Ecosystem services and human well-being in changing landscapes. Landsc. Ecol. 2013, 28, 999-1023. [CrossRef]

23. Maes, J.; Egoh, B.; Willemen, L.; Liquete, C.; Vihervaara, P.; Schägner, J.P.; Grizzetti, B.; Drakou, E.G.; La Notte, A.; Zulian, G.; et al. Mapping ecosystem services for policy support and decision making in the European Union. Ecosyst. Serv. 2012, 1, 31-39. [CrossRef]

24. Rozas-Vásquez, D.; Fuerst, C.; Geneletti, D.; Almendra, O. Integration of ecosystem services in strategic environmental assessment across spatial planning scales. Land Use Policy 2018, 71, 303-310. [CrossRef]

25. Speziale, L.; Geneletti, D. Applying an ecosystem services approach to support land-use planning: A case study in Koboko district, Uganda. Ecol. Process. 2014, 3, 10. [CrossRef]

26. Cortinovis, C.; Geneletti, D. Ecosystem services in urban plans: What is there, and what is still needed for better decisions. Land Use Policy 2019, 70, 298-312. [CrossRef]

27. Forkink, A. Benefits and challenges of using an Assessment of Ecosystem Services approach in land-use planning. J. Environ. Plan. Manag. 2017, 60, 2071-2084. [CrossRef]

28. Maes, J.; Jacobs, S. Nature-Based solutions for Europe's sustainable development. Conserv. Lett. 2017, 10, 121-124. [CrossRef]

29. Albert, C.; Aronson, J.; Fürst, C.; Opdam, P. Integrating ecosystem services in landscape planning: Requirements, approaches, and impacts. Landsc. Ecol. 2014, 29, 1285. [CrossRef]

30. Ronchi, S. Ecosystem Services for Planning: A Generic Recommendation or a Real Framework? Insights from a Literature Review. Sustainability 2021, 13, 6595. [CrossRef]

31. Wang, L.; Zheng, H.; Wen, Z.; Liu, L.; Robinson, B.E.; Li, R.; Li, C.; Kong, L. Ecosystem service synergies/trade-offs informing the supply-demand match of ecosystem services: Framework and application. Ecosyst. Serv. 2019, 37, 100939. [CrossRef]

32. Inkoom, J.N.; Frank, S.; Fürst, C. Challenges and opportunities of ecosystem service integration into land use planning in West Africa-an implementation framework. Int. J. Biodivers. Sci. Ecosyst. Serv. Manag. 2017, 13, 67-81. [CrossRef] 
33. Ministry of Land and Resources of the People's Republic of China. Control indicators for industrial lands use. Urb. Plan. Newsrep. 2008, 5, 13

34. Kabisch, N. Ecosystem service implementation and governance challenges in urban green space planning-The case of Berlin, Germany. Land Use Policy 2015, 42, 557-567. [CrossRef]

35. Woodruff, S.C.; BenDor, T.K. Ecosystem services in urban planning: Comparative paradigms and guidelines for high quality plans. Landsc. Urb. Plan. 2016, 152, 90-100. [CrossRef]

36. Spyra, M.; Kleemann, J.; Cetin, N.I.; Vázquez Navarrete, C.J.; Albert, C.; Palacios-Agundez, I.; Ametzaga-Arregi, I.; La Rosa, D.; Rozas-Vásquez, D.; Adem Esmail, B.; et al. The ecosystem services concept: A new Esperanto to facilitate participatory planning processes? Landsc. Ecol. 2019, 34, 1715-1735. [CrossRef]

37. Mascarenhas, A.; Ramos, T.B.; Haase, D.; Santos, R. Ecosystem services in spatial planning and strategic environmental assessment-A European and Portuguese profile. Land Use Policy 2015, 48, 158-169. [CrossRef]

38. Maes, J.; Teller, A.; Erhard, M.; Grizzetti, B.; Barredo, J.I.; Paracchini, M.L.; Condé, S.; Somma, F.; Orgiazzi, A.; Jones, A. Mapping and Assessment of Ecosystems and Their Services: An Analytical Framework for Ecosystem Condition; Publications Office of the European Union: Luxembourg, 2018.

39. Crossman, N.D.; Burkhard, B.; Nedkov, S.; Willemen, L.; Petz, K.; Palomo, I.; Drakou, E.G.; Martin-Lopez, B.; McPhearson, T.; Boyanova, K.; et al. A blueprint for mapping and modelling ecosystem services. Ecosyst. Serv. 2013, 4, 4-14. [CrossRef]

40. Jacobs, S.; Burkhard, B.; Van Daele, T.; Staes, J.; Schneiders, A. 'The Matrix Reloaded': A review of expert knowledge use for mapping ecosystem services. Ecol. Model. 2015, 295, 21-30. [CrossRef]

41. Benedict, M.A.; McMahon, E.T. Green Infrastructure: Linking Landscapes and Communities; Island Press: Washington, DC, USA, 2012.

42. Benedict, M.A.; McMahon, E.T. Green infrastructure: Smart conservation for the 21st century. Renew. Resour. J. $2002,20,12-17$.

43. Tzoulas, K.; Korpela, K.; Venn, S.; Yli-Pelkonen, V.; Kaźmierczak, A.; Niemela, J.; James, P. Promoting ecosystem and human health in urban areas using green infrastructure. Landsc. Urb. Plan. 2007, 81, 167-178.

44. Baycan-Levent, T.; Nijkamp, P. Planning and management of urban green spaces in Europe: Comparative analysis. J. Urb. Plan. Dev. 2009, 135, 1-12.

45. European Commission. Green Infrastructure (GI)_Enhancing Europe's Natural Capital. Available online: https://eur-lex. europa.eu/legal-content/EN/TXT/?uri=CELEX:52013DC0249 (accessed on 5 December 2013).

46. Naumann, S.; Davis, M.; Kaphengst, T.; Pieterse, M.; Rayment, M. Design, Implementation and Cost Elements of Green Infrastructure Projects; Final report; European Commission: Brussels, Belgium, 2011; p. 138.

47. Hansen, R.; Pauleit, S. From multifunctionality to multiple ecosystem services? A conceptual framework for multifunctionality in green infrastructure planning for urban areas. Ambio 2014, 43, 516-529.

48. Liquete, C.; Kleeschulte, S.; Dige, G.; Maes, J.; Grizzetti, B.; Olah, B.; Zulian, G. Mapping green infrastructure based on ecosystem services and ecological networks. A Pan-European case study. Environ. Sci. Policy 2015, 54, 268-280.

49. Madureira, H.; Andresen, T. Planning for multifunctional urban green infrastructures: Promises and challenges. Urb. Des. Int. 2013, 19, 38-49.

50. Kambites, C.; Owen, S. Renewed prospects for green infrastructure planning in the UK. Plan. Pract. Res. 2006, 21, $483-496$.

51. Kukkala, A.S.; Moilanen, A. Ecosystem services and connectivity in spatial conservation prioritization. Landsc. Ecol. 2017, 32, 5-14. [CrossRef]

52. Turner, M.G.; Donato, D.C.; Romme, W.H. Consequences of spatial heterogeneity for ecosystem services in changing forest landscapes: Priorities for future research. Landsc. Ecol. 2013, 28, 1081-1097. [CrossRef]

53. Liu, Z.; Xiu, C.; Ye, C. Improving Urban Resilience through Green Infrastructure: An Integrated Approach for Connectivity Conservation in the Central City of Shenyang, China. Complexity 2020, 2020.

54. Belote, R.T.; Dietz, M.S.; McRae, B.H.; Theobald, D.M.; McClure, M.L.; Irwin, G.H.; McKinley, P.S.; Gage, J.A.; Aplet, G.H. Identifying corridors among large protected areas in the United States. PLoS ONE 2016, 11, e0154223. [CrossRef]

55. Pauleit, S.; Liu, L.; Ahern, J.; Kazmierczak, A. Multifunctional green infrastructure planning to promote ecological services in the city. In Urban Ecology. Patterns, Processes, and Applications; Niemela, J., Ed.; Oxford University Press: Oxford, UK, 2011; pp. 272-285.

56. Chang, Q.; Liu, X.; Wu, J.; He, P. MSPA-based urban green infrastructure planning and management approach for urban sustainability: Case study of Longgang in China. J. Urb. Plan. Dev. 2015, 141, A5014006.

57. Millenium Ecosystems Assessment (MEA). Ecosystems and Human Well-Being: Wetlands and Water; World Resources Institute: Washington, DC, USA, 2005.

58. Sussams, L.W.; Sheate, W.R.; Eales, R.P. Green infrastructure as a climate change adaptation. Environ. Manag. 2015, 147, 184-193. [CrossRef]

59. Brandt, J.; Vejre, H. (Eds.) Motives, concepts and perceptions. In Multifunctional Landscapes: Volume 1 Theory, Values and History; WIT Press: Southhampton, UK, 2004; pp. 3-31.

60. von Haaren, C.; Albert, C.; Galler, C. Spatial and landscape planning: A place for ecosystem services. In Routledge Handbook of Ecosystem Services; Routledge: Abingdon-on-Thames, UK, 2016; pp. 568-581.

61. Chan, K.M.A.; Shaw, M.R.; Cameron, D.R.; Underwood, E.C.; Daily, G.C. Conservation planning for ecosystem services. PLoS Biol. 2006, 4, e379. [CrossRef] 
62. Tahri, M.; Kaspar, J.; Vacik, H.; Marusak, R. Multi-attribute decision making and geographic information systems: Potential tools for evaluating forest ecosystem services. Ann. For. Sci. 2021, 78, 1-19.

63. Martínez-Sastre, R.; Ravera, F.; González, J.A.; Santiago, C.L.; Bidegain, I.; Munda, G. Mediterranean landscapes under change: Combining social multicriteria evaluation and the ecosystem services framework for land use planning. Land Use Policy 2017, 67, 472-486. [CrossRef]

64. Sarra, A.; Nissi, E. A spatial composite indicator for human and ecosystem well-being in the Italian urban areas. Soc. Indic. Res. 2020, 148, 353-377. [CrossRef]

65. Saarikoski, H.; Mustajoki, J.; Barton, D.N.; Geneletti, D.; Langemeyer, J.; Gomez-Baggethun, E.; Marttunen, M.; Antunes, P.; Keune, H.; Santos, R. Multi-Criteria Decision Analysis and Cost-Benefit Analysis: Comparing alternative frameworks for integrated valuation of ecosystem services. Ecosyst. Serv. 2016, 22, 238-249.

66. Etxano, I.; Villalba-Eguiluz, U. Twenty-five years of social multi-criteria evaluation (SMCE) in the search for sustainability: Analysis of case studies. Ecol. Econ. 2021, 188, 107131. [CrossRef]

67. Newton, A.C.; Hodder, K.; Cantarello, E.; Perrella, L.; Birch, J.C.; Robins, J.; Douglas, S.; Moody, C.; Cordingley, J. Cost-benefit analysis of ecological networks assessed through spatial analysis of ecosystem services. J. Appl. Ecol. 2012, 49, 571-580. [CrossRef]

68. Mendoza, G.A.; Martins, H. Multi-criteria decision analysis in natural resource management: A critical review of methods and new modelling paradigms. For. Ecol. Manag. 2006, 230, 1-22.

69. Pan, H.; Zhang, L.; Cong, C.; Deal, B.; Wang, Y. A dynamic and spatially explicit modeling approach to identify the ecosystem service implications of complex urban systems interactions. Ecol. Indic. 2019, 102, 426-436. [CrossRef]

70. Chan, K.M.A.; Satterfield, T.; Goldstein, J. Rethinking ecosystem services to better address and navigate cultural values. Ecol. Econ. 2012, 74, 8-18.

71. Feizizadeh, B.; Kienberger, S. Spatially explicit sensitivity and uncertainty analysis for multicriteria-based vulnerability assessment. J. Environ. Plan. Manag. 2017, 60, 2013-2035. [CrossRef]

72. Geneletti, D. Assessing the impact of alternative land-use zoning policies on future ecosystem services. Environ. Impact Assess. Rev. 2013, 40, 22-25. [CrossRef]

73. US Census Bureau. Census Interactive Population Search. 2010. Available online: http://2010.census.gov/2010census/popmap/ (accessed on 10 December 2010).

74. Null, S.E.; Wurtsbaugh, W.A. Water development, consumptive water uses, and Great Salt Lake. In Great Salt Lake Biology; Springer: Cham, Switzerland, 2020; pp. 1-21.

75. Shaaban, K.; Horrocks, I. Poor Air Quality Along the Wasatch Front During Inversions: Role of Road Transportation and Possible Solutions. In International Conference on Applied Human Factors and Ergonomics; Springer: Cham, Switzerland, $2021 ;$ pp. $422-428$.

76. Grijseels, N.H.; Buchert, M.; Brooks, P.D.; Pataki, D.E. Using LiDAR to assess transitions in riparian vegetation structure along a rural-to-urban land use gradient in western North America. Ecohydrology 2021, 14, e2259. [CrossRef]

77. Collins, J.; Dronova, I. Urban landscape change analysis using local climate zones and object-based classification in the Salt Lake Metro Region, Utah, USA. Remote Sens. 2019, 11, 1615. [CrossRef]

78. Reynolds, J.D. Comparing Urban Vegetation Cover with Summer Land Surface Temperature in the Salt Lake Valley. Ph.D Dissertation, The University of Utah, Salt Lake City, UT, USA, 2017.

79. Utah Department of Workforce Services-Housing and Community Development Division. 2020-2024 Utah Consolidated Plan. 2020. Available online: https://www.utah.gov/pmn/files/592121.pdf (accessed on 10 December 2020).

80. CompStat. SLCPD Response Time Averages-April-September 2020. Available online: https://www.scribd.com/document/48 4047219/SLCPD-Response-Time-Averages\#from_embed (accessed on 10 December 2020).

81. Jenks, G.F. The data model concept in statistical mapping. Int. Yearb. Cartogr. 1967, 7, 186-190.

82. Scripter, M.W. Nested-means map classes for statistical maps. Ann. Assoc. Am. Geogr. 1970, 60, $385-392$.

83. Langemeyer, J.; Wedgwood, D.; McPhearson, T.; Baró, F.; Madsen, A.L.; Barton, D.N. Creating urban green infrastructure where it is needed-A spatial ecosystem service-based decision analysis of green roofs in Barcelona. Sci. Total Environ. 2020, 707, 135487. [CrossRef]

84. Qu, Y.; Lu, M. Identifying conservation priorities and management strategies based on ecosystem services to improve urban sustainability in Harbin, China. PeerJ 2018, 6, e4597.

85. McPhearson, T.; Pickett, S.T.A.; Grimm, N.B.; Niemelä, J.; Alberti, M.; Elmqvist, T.; Weber, C.; Haase, D.; Breuste, J.; Qureshi, S. Advancing urban ecology toward a science of cities. BioScience 2016, 66, 198-212. [CrossRef]

86. Wolff, S.; Schulp, C.J.E.; Verburg, P.H. Mapping ecosystem services demand: A review of current research and future perspectives. Ecol. Indic. 2015, 55, 159-171. [CrossRef]

87. McKinstry, M.C.; Hubert, W.A.; Anderson, S.H. Wetland and Riparian Areas of the Intermountain West: Ecology and Management; University of Texas Press: Austin, TX, USA, 2004; Volume 4.

88. Salas-Zapata, W.A.; Ortiz-Muñoz, S.M. Analysis of meanings of the concept of sustainability. Sustain. Dev. 2019, $27,153-161$. [CrossRef]

89. Swart, R.; Raskin, P.; Robinson, J. The problem of the future: Sustainability science and scenario analysis. Glob. Environ. Change 2004, 14, 137-146. [CrossRef]

90. Burkhard, B.; Kroll, F.; Nedkov, S.; Müller, F. Mapping ecosystem service supply, demand and budgets. Ecol. Indic. 2012, 21, 17-29. [CrossRef] 
91. Ramyar, R. Social-ecological mapping of urban landscapes: Challenges and perspectives on ecosystem services in Mashhad, Iran. Habitat Int. 2019, 92, 102043. [CrossRef]

92. Stavros, G.; Turner, R.K. Valuing Ecosystem Services: The Case of Multi-Functional Wetlands; Routledge: Abingdon-on-Thames, UK, 2012.

93. Bixler, R.P.; Lieberknecht, K.; Leite, F.; Felkner, J.; Oden, M.; Richter, S.M.; Atshan, S.; Zilveti, A.; Thomas, R. An observatory framework for metropolitan change: Understanding urban social-ecological-technical systems in texas and beyond. Sustainability 2019, 11, 3611. [CrossRef] 